\title{
Sexual Difference in Bone Geometry of Adult Patients with Classical Congenital Adrenal Hyperplasia: Data Using Peripheral Quantitative Computed Tomography
}

\author{
Susanne Bechtold ${ }^{a}$ Andreas Beyerlein ${ }^{b}$ Walter Bonfig ${ }^{a}$ Robert Dalla Pozza ${ }^{a}$ \\ Stephanie Putzker ${ }^{\mathrm{a}}$ Ragna Otto ${ }^{\mathrm{a}}$ Heinrich Schmidt ${ }^{\mathrm{a}}$ Hans Peter Schwarz ${ }^{\mathrm{a}}$ \\ a Division of Endocrinology and Diabetology, University Children's Hospital, Ludwig Maximilians University, and \\ ${ }^{\mathrm{b}}$ Division of Epidemiology, Helmholtz Institution, Munich, Germany
}

\section{Key Words}

Bone geometry · Congenital adrenal hyperplasia .

Androgens · Periosteal bone apposition - Glucocorticoids .

Osteoporosis

\begin{abstract}
Background/Aims: Glucocorticoid treatment may influence bone and muscle development in patients with congenital adrenal hyperplasia (CAH). This study evaluated bone mineral density (BMD), bone geometry and muscle mass. Methods: 73 adult patients with classical CAH were followed. $B M D$, bone geometry and muscle mass were measured using peripheral quantitative computed tomography (pQCT). Glucocorticoid-equivalent doses throughout life were calculated and at the time PQCT androgen levels were measured. Results: In males the mean standard deviation (SD) score for trabecular BMD $(-0.33 \pm 0.71)$ was reduced, whereas mean cortical BMD (1.05 \pm 1.11$)$ was elevated. Mean total ( $0.86 \pm$ $1.12)$ and medullary cross-sectional area (CSA; $1.12 \pm 1.17)$ were significantly increased $(p<0.001)$. In all patients SD scores for cortical thickness $(-0.65 \pm 0.91)$ and muscle CSA $(-0.83 \pm 0.91)$ were reduced. Treatment duration was associated with lower trabecular BMD in males $(r=-0.63, p<$ 0.001). Suppressed androgens and simple virilizing CAH had
\end{abstract}

\section{KARGER}

E-Mail karger@karger.com

www.karger.com/hrp an adverse effect on the muscle CSA SD score (OR 0.58 and 0.46 , respectively, $p<0.05)$. Conclusion: There was a sexual difference with enlarged total and medullary CSA in females, whereas in males trabecular BMD was reduced and cortical BMD elevated. Cortical thickness and muscle CSA were reduced in all CAH patients with a possible long-term impact on bone development and stability. Monitoring of bone and muscle development might be warranted.

C 2014 S. Karger AG, Basel

\section{Introduction}

Congenital adrenal hyperplasia $(\mathrm{CAH})$ is a group of autosomal recessive disorders resulting from deficiency of one of the five enzymes required for cortisol synthesis in the adrenal cortex. 21-Hydroxylase deficiency is the most frequent cause, accounting for more than $90 \%$ of all $\mathrm{CAH}$ cases. The majority of patients have a severe enzyme deficiency that results in the salt wasting (SW) form with insufficient aldosterone and cortisol biosynthesis. The result of a less severe deficiency is the simple virilizing (SV) form with insufficient production of cortisol. Patients with 21-hydroxylase deficiency require long-term glucocorticoid (GC) treatment. Most patients need the addi- 
tion of mineralocorticoids. GCs both replace the deficient cortisol and reduce the overstimulation of the adrenal cortex [1]. It is quite difficult to reduce excess androgen without giving higher GC doses [2]. Finding the balance between too much and too little GC treatment is especially difficult because current available GCs do not allow to replicate the physiological circadian rhythm of cortisol secretion [3].

Evidence exists regarding the potential impact of longterm GC treatment on bone mineral density (BMD), bone geometry and muscle development in adults with $\mathrm{CAH}$ [4]. Chronic GC therapy is a known risk factor for osteoporosis [5]. On the other hand, androgens may be osteoprotective. The osteoblastic effect of androgens is thought to be mediated by estrogen receptors with stimulation of bone formation $[6,7]$. In patients with $\mathrm{CAH}$, published data are conflicting with BMD values being reported as unchanged, elevated or reduced [8-10]. A wide range of age at investigation, heterogeneous groups including classical and non-classical forms, variable GC dose and form, and inclusion of pre- and postpubertal patients might explain in part the differences between studies $[8,11,12]$.

Most studies on BMD in CAH used dual-energy X-ray absorptiometry (DXA) measurements [4]. However, since the densitometric data obtained by DXA are greatly influenced by bone size, the height and weight of the subjects must be considered. This is an important issue as $\mathrm{CAH}$ patients have a final height at the lower limit of normal [13]. Peripheral quantitative computed tomography (pQCT) images a cross-sectional view of the limb and provides volumetric, three-dimensional assessment of the structural (BMD) and geometric properties (bone size) of the appendicular skeleton - information which is not provided by DXA. A further advantage of $\mathrm{PQCT}$ is its ability to measure the muscle cross-sectional area (CSA) of the limb.

The cohort consisted of adolescent and adult male and female patients with classical CAH. Our objective was to study the impact of chronic GC treatment on bone mass, density, geometry and the muscle-bone relation at the radius using $\mathrm{PQCT}$.

\section{Subjects and Methods}

We followed 73 patients (36 female) born between 1966 and 1992 with 21-hydroxylase deficiency continuously from infancy until adulthood in our tertiary health care center (Division of Endocrinology, University Children's Hospital of Munich). The diagnosis of classical CAH was based on both clinical symptoms and signs and on hormonal analysis and was confirmed by subsequent comprehensive genotyping [14]. At the time of diagnosis, newborn screening for CAH was not yet available. 41 (20 female) patients had SW CAH and 32 (16 female) had the SV form. Patients with additional diseases possibly affecting bone development were not included in this cross-sectional study ( 2 patients with seizure and anticonvulsive treatment). All patients had received hydrocortisone (HC) three times daily for GC replacement during their growth period with the exception of 2 who were treated with prednisone. Thereafter, some switched to longer-acting GCs [dexamethasone in 3 ( 1 female), prednisone in 28 ( 16 female)]. GC doses were converted to cortisol equivalents using growth-retarding equivalents $(80 \mathrm{mg} \mathrm{HC}=16 \mathrm{mg}$ prednisone $=1 \mathrm{mg}$ dexamethasone) [15]. Mean daily GC doses per square meter of body surface area were analyzed at start of puberty, at final height and in adolescent/adulthood at the time of pQCT measurement. pQCT measurement was performed between 2002 and 2010 in all adolescent and adult patients before transition to the adult clinic.

Anthropometric data were compared with the cross-sectional growth data of Brandt and Reinken [16]. The pQCT results were compared with data of adult participants of the Donald study or their parents of similar age range (15.0-9.9 years) measured with identical methodology $[17,18]$. Additionally, we used height-specific reference data from the same population.

Height was measured in the standing position to the nearest $1 \mathrm{~mm}$ using a digital telescopic wall-mounted stadiometer (Ulmer Stadiometer; Prof. E. Heinze, Ulm, Germany). Weight was determined to the nearest $0.1 \mathrm{~kg}$ using an electronic scale (Seca $753 \mathrm{E}$; Vogel \& Hanke, Hamburg, Germany) with the patients clothed in underwear. Forearm length was measured at the non-dominant forearm as the distance between the ulnar styloid process and the olecranon using a caliper. At start of puberty, defined by Tanner stage B2 in females and testicular volume $>3 \mathrm{ml}$ in males [19], bone age was determined on an X-ray of the left hand and wrist by the method of Greulich and Pyle [20].

\section{Peripheral Quantitative Computed Tomography}

Two sites of the non-dominant radius were analyzed by pQCT (XCT 2000 Scanner; Stratec, Inc., Pforzheim, Germany), the distal metaphysis (' $4 \%$ site') and the proximal diaphysis (' $65 \%$ site') as described before $[17,21]$. The measurement was performed on the radius whose distance to the radial articular surface corresponded to 4 and $65 \%$ of forearm length. At both sites a 2 -mm-thick single tomographic slice was sampled at a voxel size of $0.4 \mathrm{~mm}$. Image processing and calculation of numerical values was done using the manufacturer's version 5.40 software package (Stratec, Inc.).

At the distal radius (metaphyseal site) trabecular BMD, at the proximal radius (diaphyseal site) cortical BMD, bone mineral content (BMC), total CSA, cortical CSA and cortical thickness were measured. Further, muscle CSA was calculated by the manufacturer's software.

\section{Endocrine and Metabolic Assessment}

At the time of bone evaluation a routine blood analysis (blood cell count, electrolytes, and liver and renal function tests) was obtained. Blood samples were taken in the morning in all subjects. 17-Hydroxyprogesterone (17-OHP) was assayed by an enzyme immunoassay (IBL, Hamburg, Germany) and androstenedione and testosterone by commercial enzyme-labeled immunometric chemiluminescence assay (Immulite; Siemens, Eschborn, Germa- 
Table 1. Auxology, medication and serological data in adult CAH patients divided by sex and subtype

\begin{tabular}{|c|c|c|c|c|}
\hline \multirow[t]{2}{*}{ Parameters } & \multicolumn{2}{|l|}{ Females $(\mathrm{n}=36)$} & \multicolumn{2}{|l|}{ Males $(n=37)$} \\
\hline & $\mathrm{SW}(\mathrm{n}=20)$ & SV $(n=16)$ & $\mathrm{SW}(\mathrm{n}=21)$ & SV $(n=16)$ \\
\hline Age at investigation, years & $20.7(16.7-36.4)$ & $30.4(16.2-43.7)^{\mathrm{a}}$ & $21.3(17.8-43.0)$ & $21.1(17.1-42.5)$ \\
\hline Age at diagnosis, years & $0.19 \pm 0.09$ & $1.03 \pm 1.66^{\mathrm{a}}$ & $0.38 \pm 1.15$ & $2.74 \pm 1.81^{\mathrm{a}}$ \\
\hline Final height, cm & $161.70 \pm 4.86$ & $157.50 \pm 7.54^{\mathrm{a}}$ & $170.20 \pm 6.96$ & $170.0 \pm 6.67$ \\
\hline Final height SD score & $-0.45 \pm 0.84^{\mathrm{b}}$ & $-1.35 \pm 1.29^{\mathrm{a}}$ & $-1.04 \pm 1.03^{b}$ & $-1.13 \pm 0.94$ \\
\hline BA advanced at puberty start, years & $0.09 \pm 0.3$ & $0.55 \pm 0.52^{\mathrm{a}}$ & $0.50 \pm 0.52^{\mathrm{b}}$ & $0.55 \pm 0.53^{\mathrm{a}}$ \\
\hline Age at menarche, years & $13.82 \pm 1.64$ & $13.79 \pm 2.11$ & - & - \\
\hline HC-E dose at puberty start & $15.19 \pm 3.61$ & $19.39 \pm 5.32^{\mathrm{a}}$ & $19.48 \pm 8.06$ & $20.18 \pm 4.53$ \\
\hline $\mathrm{HC}-\mathrm{E}$ at $\mathrm{FH}$ & $16.75 \pm 4.25$ & $19.84 \pm 4.19$ & $19.29 \pm 4.04$ & $18.98 \pm 2.71$ \\
\hline HC-E at present & $17.43 \pm 5.10$ & $18.00 \pm 4.46$ & $19.52 \pm 4.99$ & $19.58 \pm 4.23$ \\
\hline BMI SD score & $0.79 \pm 1.08^{\mathrm{b}}$ & $0.76 \pm 1.87^{\mathrm{b}}$ & $0.72 \pm 1.27^{\mathrm{b}}$ & $0.25 \pm 1.14$ \\
\hline 17-OHP, nmol/1 & $6.6(1.21-297)$ & $7.3(0.42-248)$ & $7.6(1.45-226)$ & $10.12(1.91-227)$ \\
\hline Androstenedione, nmol/l & $1.86(0.66-73.5)$ & $1.96(0.52-73.5)$ & $2.94(1.26-27.6)$ & $2.83(1.05-178.2)$ \\
\hline DHEAS, $\mu \mathrm{mol} / \mathrm{l}$ & $0.20(0.14-2.70)$ & $0.25(0.14-2.29)$ & $1.01(0.14-11.91)$ & $1.48(0.46-13.27)$ \\
\hline Testosterone, nmol/l & $1.93(0.40-13.19)$ & $0.93(0.52-3.12)$ & $14.26(5.55-31.82)$ & $13.10(2.14-25.33)$ \\
\hline
\end{tabular}

Data are shown as mean \pm SD or median (range) as indicated. BA $=$ Bone age. ${ }^{\text {a }}$ Significant difference between SV and SW CAH (for males and females; Student's t test or Mann-Whitney U test, if appropriate). ${ }^{b}$ Significant difference compared to a healthy reference population (Student's t test).

ny). Dehydroepiandrosterone sulfate (DHEAS) was assayed by commercial electrochemiluminescence immunoassay (Elecsys 2010; Roche Diagnostics, Mannheim, Germany) in our laboratory. Test sensitivities were $0.08 \mathrm{nmol} / 1$ for $17-\mathrm{OHP}$ and androstenedione, $0.02 \mathrm{nmol} / \mathrm{l}$ for testosterone, and $0.003 \mu \mathrm{mol} / \mathrm{l}$ for DHEAS. Intra- and interassay variations were 6 and $11.3 \%$ for 17-OHP, 8.1 and $9.8 \%$ for androstenedione, 3.8 and $6.2 \%$ for testosterone, and 3.5 and $4.6 \%$ for DHEAS.

\section{Statistical Analysis}

Anthropometric measurements of $\mathrm{CAH}$ patients were converted into sex-, age- and height-specific standard deviation (SD) scores using the formula: $\mathrm{SD}$ score $=[$ (test result for a patient $)-$ (age- or height-specific mean in reference population)]/(age- or height-specific SD in reference population). Results are presented as mean \pm SD. Differences from an age-matched healthy population were tested by one-sample $t$ test of the mean SD score against zero. For between-group comparisons (SW vs. SV, female vs. male) we used Student's t test and in case of non-normally distributed variables the non-parametric Mann-Whitney U test. Correlations between variables were determined by Pearson's method.

We performed a linear regression analysis to evaluate the associations between different bone parameters such as trabecular $\mathrm{BMD}$, cortical BMD, total bone CSA, cortical thickness and muscle CSA (SD scores) (separate dependent variables) and body mass index (BMI), final height SD score, $\mathrm{HC}$-equivalent dose per square meter body surface area (at start of puberty, at final height and at present), and the binary variables diagnosis ( $\mathrm{SW}=0$ vs. $\mathrm{SV}=1)$ and suppressed adrenal androgens (suppressed $=0$ vs. not suppressed $=1$ ) (predictors), additionally adjusted for sex and age. Backward variable selection was also applied based on the Akaike Information Criterion [22].

Altered Bone Geometry in Adult CAH
Throughout the level of significance for each test was set to 0.05. Calculations were performed using the statistical package SPSS for Windows (version 14.0; SPSS, Inc., Chicago, Ill., USA) and R-2.12 (http://cran.r-project.org). The study protocol was approved by the Ethics Committee of Ludwig Maximilians University, Munich, and by the Federal Office for Radiation Protection. Informed consent was obtained from all patients and/or their parents.

\section{Results}

\section{Auxological Data and Medication}

Patients with SW CAH were diagnosed early at a mean age of $0.07 \pm 0.19$ years (range $0.0-0.5$, median 0 ), whereas patients with the SV form were diagnosed a mean age of $1.96 \pm 1.95$ years (range $0.0-6.0$, median 1.5 ). None of the patients had suffered from adrenal crisis once SW $\mathrm{CAH}$ was diagnosed. Table 1 summarizes the auxological data of the study population divided by sex and type of $\mathrm{CAH}$

Females with SV CAH were significantly older than females with SW CAH ( $\mathrm{p}=0.004)$. Mean final height was $159.9 \pm 6.5 \mathrm{~cm}(-0.85 \pm 1.14$ SDS $)$ in females, those with SW being significantly taller $(\mathrm{p}=0.017)$. Mean final height in males was $170.1 \pm 6.8 \mathrm{~cm}(-1.08 \pm 0.99)$. There was no significant height difference between male SW and SV. BMI SD score was significantly higher than in the 
Table 2. BMD and bone geometry parameters in adult CAH patients divided by sex and subtype

\begin{tabular}{lccccc}
\hline Parameters (SD scores) & \multicolumn{2}{l}{ Females $(\mathrm{n}=36)$} & & \multicolumn{2}{l}{ Males $(\mathrm{n}=37)$} \\
\cline { 2 - 3 } \cline { 5 - 6 } & SW $(\mathrm{n}=20)$ & SV $(\mathrm{n}=16)$ & & SW $(\mathrm{n}=21)$ & SV $(\mathrm{n}=16)$ \\
\hline Trabecular BMD & $-0.24 \pm 0.74$ & $-0.09 \pm 0.94$ & & $-0.35 \pm 0.74^{\mathrm{a}}$ & $-0.32 \pm 0.67^{\mathrm{a}}$ \\
Cortical BMD & $0.18 \pm 1.13$ & $0.07 \pm 1.18$ & & $1.12 \pm 1.17^{\mathrm{a}}$ & $0.95 \pm 1.05^{\mathrm{a}}$ \\
Total CSA & $0.94 \pm 1.36^{\mathrm{a}}$ & $0.75 \pm 1.07^{\mathrm{a}}$ & & $-0.21 \pm 0.91$ & $0.05 \pm 0.98$ \\
Medullary CSA & $1.12 \pm 1.17^{\mathrm{a}}$ & $1.11 \pm 1.21^{\mathrm{a}}$ & & $0.06 \pm 0.71$ & $0.40 \pm 0.68^{\mathrm{a}}$ \\
Cortical CSA & $0.16 \pm 1.17$ & $-0.30 \pm 1.19$ & & $-0.46 \pm 1.22$ & $-0.53 \pm 1.14$ \\
Cortical thickness & $-0.64 \pm 0.82^{\mathrm{a}}$ & $-0.93 \pm 1.08^{\mathrm{a}}$ & & $-0.45 \pm 0.96^{\mathrm{a}}$ & $-0.65 \pm 0.77^{\mathrm{a}}$ \\
BMC & $0.03 \pm 1.32$ & $-0.31 \pm 1.22$ & & $-0.49 \pm 1.18$ & $-0.62 \pm 1.30$ \\
Muscle CSA & $-0.82 \pm 1.02^{\mathrm{a}}$ & $-0.76 \pm 1.08^{\mathrm{a}}$ & & $-1.09 \pm 0.86^{\mathrm{a}}$ & $-0.58 \pm 0.56^{\mathrm{a}, \mathrm{b}}$
\end{tabular}

Data are shown as mean \pm SD. ${ }^{a}$ Significant difference between $\mathrm{CAH}$ patients and a healthy reference population, $\mathrm{p}<0.05$. $^{\mathrm{b}}$ Significant difference between CAH subtype within sex groups, $\mathrm{p}<0.05$.

reference population in all patients apart from males with SV CAH. Bone age at start of puberty was comparable in male (both groups) and female SV with about +0.5 years advanced. However, bone age was almost identical with chronological age in female SW. In addition, all patients had entered and completed puberty at a normal age range. Females had regular menses with 4 of them being on contraceptives, and boys had a mean testicular volume of 18 $\pm 2.3 \mathrm{ml}$ with normal adult plasma testosterone values.

\section{Biochemical Evaluation}

Considering the whole group of $\mathrm{CAH}$ patients, the underlying disease was well controlled in the majority of patients, as indicated by the slightly advanced bone age at start of puberty, final height and laboratory parameters. DHEAS concentrations were consistently below normal for age, androstenedione levels mostly within the normal range, whereas 17-OHP levels were significantly elevated in comparison to the reference data but within the accepted range of up to $30 \mathrm{nmol} / \mathrm{l}$ in the majority of patients. In a subgroup analysis, 17 patients seem to be overtreated with a combination of suppressed DHEAS levels $(\leq 0.14$ $\mu \mathrm{mol} / \mathrm{l}), 17$-OHP levels $<5.4 \mathrm{nmol} / \mathrm{l}$ as well as low androstenedione values $<3.5 \mathrm{nmol} / \mathrm{l}$. In 15 patients, $17-\mathrm{OHP}$ levels were $>30 \mathrm{nmol} / \mathrm{l}$ combined with elevated androgen levels possibly due to a too low dose or a lack of compliance.

\section{BMD and Bone Geometry Results}

In male $\mathrm{CAH}$ patients there was a significant reduction in trabecular BMD SD score $(-0.33 \pm 0.71)$, whereas cortical BMD SD score $(1.05 \pm 1.11)$ was elevated. Total CSA SD score was normal $(-0.10 \pm 0.93)$ and medullary cavity

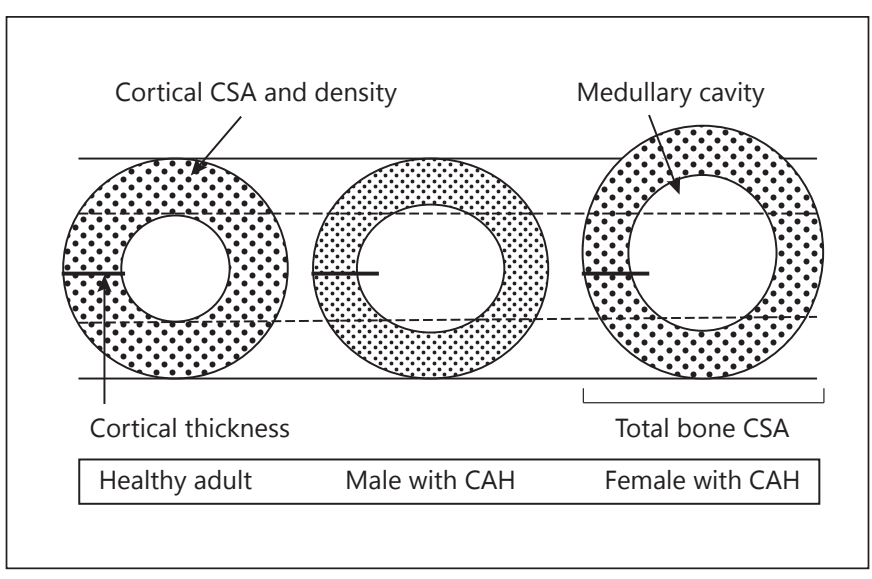

Fig. 1. Schematic, cross-sectional view of the appendicular skeleton in male and female CAH adults: the result of an enlarged medullary cavity is a smaller cortical thickness. In females, total CSA of the bone is larger in relation to a healthy reference population (left side). In males, cortical BMD is elevated indicated by a reduced number of points within the cortex (less porosity).

SD score was slightly elevated $(0.21 \pm 0.71, \mathrm{p}=0.081)$, therefore SD scores of cortical CSA $(-0.49 \pm 1.17)$ and cortical thickness $(-0.54 \pm 0.88)$ were significantly reduced ( $\mathrm{p}=0.016$ and 0.001 , respectively) (fig. 1). Muscle CSA SD score $(-0.87 \pm 0.78)$ was reduced ( $p<0.001)$, also after adjustment for height $(-0.64 \pm 0.43, \mathrm{p}<0.05)$. There was a difference in muscle CSA between male subtype of $\mathrm{CAH}$ with significantly higher values in $\mathrm{SV}(\mathrm{p}=0.05$; table 2).

In female patients, BMD parameters (trabecular, cortical) were within the normal range, total $(0.86 \pm 1.12)$ and medullary CSA SD score $(1.12 \pm 1.17)$ were significantly 

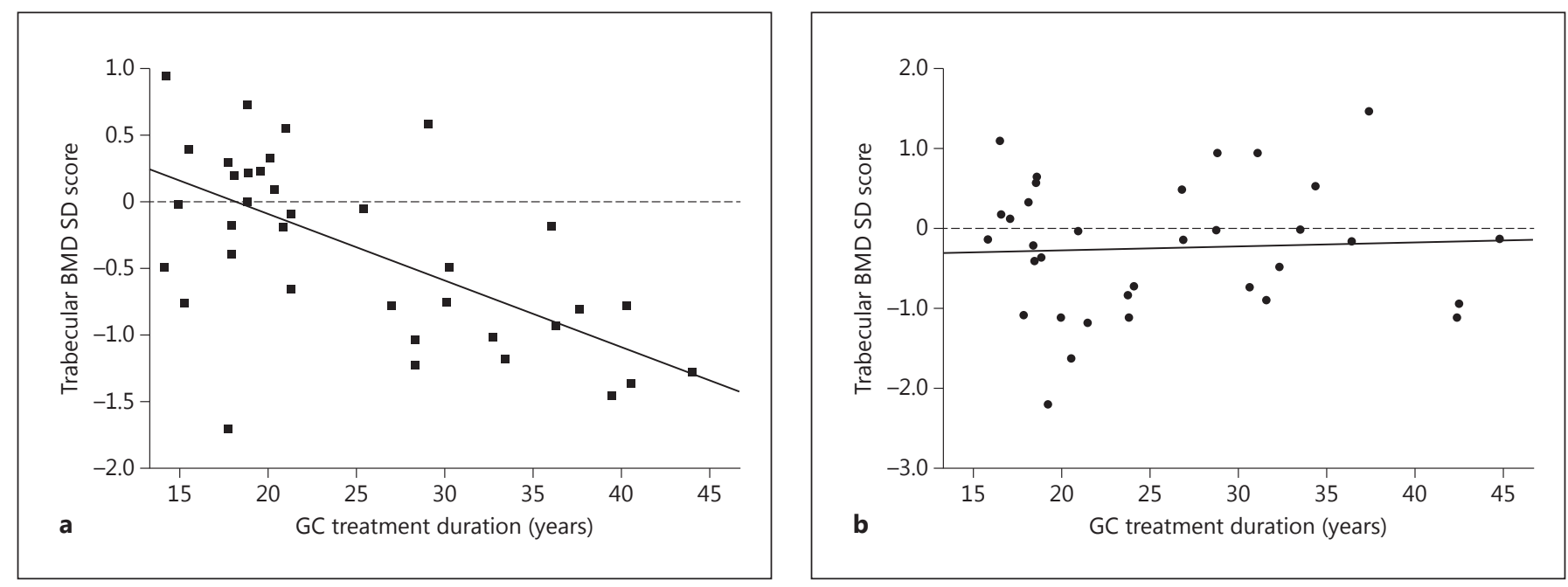

Fig. 2. Relation of GC treatment duration with trabecular BMD SD scores in patients with CAH: upper panel shows the relation for males (a, black squares), lower panel shows the relation for females (b, black dots).

larger $(<0.001)$ than in the reference population, with the consequence of a reduced cortical thickness $(-0.77 \pm 0.94$, $\mathrm{p}<0.001)$ (fig. 1). As in male patients the muscle CSA SD score was reduced $(-0.79 \pm 1.03, \mathrm{p}<0.001)$.

\section{Relationship between BMD/Bone Geometry and Other Parameters}

In the whole patient population no significant influence on bone parameters by present $\mathrm{HC}$-equivalent dose, dose at onset of puberty or at the age near final height was detectable. When we built groups using a cut-off level for $\mathrm{HC}$-equivalent dose at the different time points (onset of puberty, at final height and at present) of $17 \mathrm{mg} / \mathrm{m}^{2}$, as recommended in the literature [2], again no significant differences were detectable. 23 patients were overweight and had a BMI above the 90th percentile. No significant difference with regard to bone parameters between normal and overweight patients was observed. The BMI correlated with the muscle mass in all $(\mathrm{r}=0.38$ for males and $\mathrm{r}=0.55$ for females, $\mathrm{p}<0.02$ ), leading to a trend for a higher muscle mass with increasing BMI. Treatment duration and age at evaluation might play a role. In males, duration of GC treatment was negatively associated with trabecular BMD $(\mathrm{r}=-0.63, \mathrm{p}<0.001)$ and BMC $(\mathrm{r}=$ $-0.33, \mathrm{p}=0.048)$, while no association was found in females (fig. 2).

Some of our patients were considered to be overtreated with androgen levels almost suppressed. Performing a comparison between overtreated $(n=17)$, normal treated $(\mathrm{n}=43)$ and undertreated or less compliant $(\mathrm{n}=15)$ patients, those with overtreatment had the smallest muscle CSA $(-1.30 \pm 0.69$ vs. $-0.52 \pm 0.66$ for undertreated, $\mathrm{p}<$ $0.001)$. Patients with serological signs of undertreatment were more prone to be treated by HC (74\%), whereas in normal or overtreated CAH patients, 40 and $50 \%$, respectively, were on long-acting GC (prednisone or dexamethasone).

In multiple regression models (table 3 ) adjusted for age and sex, HC-equivalent dose per square meter at final height was positively associated with trabecular BMD SD score $(\beta=0.07 ; 95 \%$ CI $0.00,0.13)$ but negatively with cortical thickness $(\beta=-0.07 ; 95 \%$ CI $-0.13,-0.01)$ after backward selection. The present HC-equivalent dose did not show a significant influence on bone density or geometry (data not shown). Lower muscle CSA SD score was associated negatively with the diagnosis of SV $(\beta=-0.46$; $95 \% \mathrm{CI}-0.81,-0.11)$, but positively with $\mathrm{BMI}(\beta=0.13$; $95 \%$ CI $0.09,0.17)$ and suppressed androgens $(\beta=0.57$; $95 \%$ CI $0.12,1.03)$. There were no significant associations between cortical BMD and total CSA and any of the predictors (data not shown).

\section{Discussion}

To the best of our knowledge this is the first study using PQCT for the evaluation of bone density and geometry in classical CAH patients. The most striking findings 
Table 3. Linear regression models for bone parameters: potential predictive factors

\begin{tabular}{|c|c|c|c|c|c|c|c|}
\hline & $\begin{array}{l}\text { Trabecular BMD } \\
\text { SD score }\end{array}$ & $\begin{array}{l}\text { Cortical BMD } \\
\text { SD score }\end{array}$ & $\begin{array}{l}\text { Total CSA } \\
\text { SD score }\end{array}$ & $\begin{array}{l}\text { Cortical thickness } \\
\text { SD score }\end{array}$ & $\begin{array}{l}\text { Cortical thickness } \\
\text { SD score post-BW }\end{array}$ & $\begin{array}{l}\text { Muscle CSA } \\
\text { SD score }\end{array}$ & $\begin{array}{l}\text { Muscle CSA } \\
\text { SD score post-BW }\end{array}$ \\
\hline BMI & $0.02(-0.03,0.06)$ & $0.01(-0.06,0.07)$ & $-0.04(-0.02,0.11)$ & $0.05(-0.01,0.10)$ & \multirow{5}{*}{$-0.07(-0.13,-0.01)$} & $0.13(0.08,0.17)$ & \multirow[t]{3}{*}{$0.13(0.09,0.17)$} \\
\hline HCE puberty & $-0.01(-0.05,0.03)$ & $-0.01(-0.07,0.05)$ & $-0.01(-0.07,0.05)$ & $0.02(-0.03,0.07)$ & & $0.04(0.00,0.07)$ & \\
\hline $\mathrm{HCE}$ at FH & $0.07(0.00,0.13)$ & $0.06(-0.04,0.16)$ & $0.02(-0.08,0.12)$ & $0.07(-0.15,0.01)$ & & $-0.05(-0.12,0.01)$ & \\
\hline Diagnosis & $-0.21(-0.59,0.17)$ & $-0.07(-0.63,0.5)$ & $-0.04(-0.60,0.52$ & $0.09(-0.35,0.54)$ & & $-0.46(-0.81,-0.11)$ & $-0.48(-0.84,-0.12)$ \\
\hline Suppression & $0.24(-0.26,0.74)$ & $-0.63(-1.37,0.12)$ & $0.13(-0.61,0.87)$ & $0.38(-0.21,0.97)$ & & $0.57(0.11,1.04)$ & \\
\hline
\end{tabular}

Values are presented as $\beta(95 \% \mathrm{CI})$. Bold values determine significant associations. $\beta=$ Regression coefficient; $\mathrm{FH}=$ final height (expressed as SD score according to Brandt and Reinken [16]); HCE puberty = HC-equivalent dose per square meter at onset of puberty; HCE at FH = HC-equivalent dose per square meter at final height; Diagnosis = SW CAH classified $=0, \mathrm{SV} C A H=1$; Suppression $=$ defined as low DHEAS and androstenedione levels at pQCT evaluation $(=0)$; post-BW $=$ selected variables according to backward selection

of this study were reduced cortical thickness and muscle CSA in all patients. In females bone geometry was altered with enlarged total and medullary CSA, whereas in males trabecular BMD was reduced and cortical BMD elevated.

There are a number of studies in the literature that assessed BMD in individuals with CAH with a wide spectrum of results. DXA was the technique mostly used. However, caution is necessary with this technique since it is dependent on bone and body size. $\mathrm{CAH}$ adults have a reduced final height and therefore underestimated BMD data might be the consequence of DXA measurement. We therefore used the PQCT method which gives data on real volumetric BMD and bone geometry.

In this population, trabecular BMD appeared to be maintained in female but not in male $\mathrm{CAH}$ patients. This is in accordance with previous reports on lower BMD values in males [11,23]. Further, in male $\mathrm{CAH}$ patients cortical BMD was significantly elevated. The reduction in trabecular and elevation in cortical BMD could be the consequence of long-term GC treatment characterized by lower bone turnover [24]. Women with CAH might benefit from the preserving effect of estrogens combined with the additive effect of androgens [25]. In males the elevated adrenal androgens may suppress the hypothalamicgonadal axis with the result of smaller testes and lower testosterone, thereby influencing bone development [26].

The BMI of CAH patients was significantly higher as in most previous studies [13, 23, 27]. BMI also appeared to protect patients with CAH from bone loss. Chakhtoura et al. [23] could show that a higher BMI was associated with a higher bone density in adult patients with CAH. In this study an increase in BMI by 1 point was associated with an increase in muscle mass by $0.13 \mathrm{SD}$. BMI had no influence on BMD or bone geometry parameters. However, looking at patients below the age of 30 years, there was a significant correlation between BMI and total CSA $(\mathrm{r}=0.32)$ and medullary CSA $(\mathrm{r}=0.31)$.
There seems to be a difference in results with regard to which age group was chosen in the different studies. Disease duration or age is known to be an important confounding factor $[28,29]$. In previous studies with a younger patient population ( $<30$ years of age) normal values of trabecular BMD at the spine were described $[9,28,30$, 31 . With increase in age of the population $(>30$ years of age) lower BMD levels were found $[4,8,22]$. One explanation for this relation might be the cumulative lifelong GC dose $[12,31,32]$. A second explanation might be the higher GC dosing used in infancy in those of older age. Further, in young adults the negative effect of GC on bone could be balanced by the positive effects of androgens [28, 33]. In this study with longer disease duration and therefore higher cumulative GC dose, patients had a lower trabecular BMD and a lower bone mass. In patients with Addison disease, low BMD was found especially in males with low testosterone and in postmenopausal women [34]. This scenario may also apply for older CAH patients.

Cortical thickness was reduced in males and females possibly as a result of increased endosteal bone resorption as a consequence of GC treatment [5]. GC dosing at a single time point as at final height had only a mild influence, e.g. with each increase in HC-equivalent dose at final height of $1 \mathrm{mg} / \mathrm{m}^{2}$ a decrease of cortical thickness SD score by 0.07 was associated.

Total and medullary CSA were significantly elevated in female $\mathrm{CAH}$ patients, but not in males (apart from a significant elevation of medullary cavity in male SV). In females, bone geometry might be altered in favor of periosteal bone apposition. This could be explained by early influences of androgens on bone development. Androgens enhance osteoblast differentiation and influence osteoclast activity. In both sexes androgens may stimulate periosteal apposition [35]. In males with lower levels of estrogens, periosteal apposition might be upregulated, 
whereas in females endogenous estrogens may inhibit periosteal apposition through interaction with IGF-1 [36]. Recent evidence suggests that the higher IGF-1 levels in males may depend on neonatal androgen action [37]. In females with $\mathrm{CAH}$ and elevated androgens from early on in life, it is suggestive that androgens are responsible for an elevated total and medullary CSA.

Androgens additionally increase muscle mass and strength [7]. Surprisingly, muscle mass was low in all CAH patients, especially in SV CAH. This may have long-term consequences on bone development since the largest bone loads come from muscle force. Consequently, chronically reduced muscle forces result in a disuse osteopenia.

There was no significant association between BMD, bone geometry and 17-OHP or androstenedione and also no influence of present HC-equivalent dose. However, overtreated patients had the lowest muscle mass, indicating treatment induced sarcopenia. Previous studies could demonstrate the effect of GC overdosing only on BMD in adult $\mathrm{CAH}$ [12]. Future studies have to evaluate if a lower dose in infancy and during pubertal years has an impact on muscle and bone development. In general, overtreatment with GC has to be avoided.

An advantage of our study is a regular follow-up of adolescent and adult patients with classical CAH in a single outpatient clinic treated similarly. Appropriateness of their GC dose was checked based on their steroid serum and urine concentration, growth and development. A weakness is its cross-sectional design and a relatively small sample resulting in small numbers in the four subgroups and a heterogeneous age distribution. No data on physical activity and diet were collected. Further, espe- cially older patients were treated with higher doses in infancy and throughout childhood that might have had an influence on bone development. Serological and morphological measures recorded represent only one window in time. Patient's compliance and response to medication may greatly vary over time.

To conclude, the population at particular risk might be male patients with a long GC treatment duration, a lower $\mathrm{BMI}$, low muscle mass and suppressed androgens. In females, estrogens and androgens may have an additive effect on bone development leading to bone expansion, at least in the younger age group. We may suppose that with age $\mathrm{CAH}$ patients develop lower BMD. Physicians should bear in mind the potential consequences of GC on bone by adjusting the treatment and improve clinical and laboratory surveillance from infancy on [23]. It is important to use the lowest possible GC dose. Lifelong proficient medical care for $\mathrm{CAH}$ patients should be assured. Followup BMD measurements in adults are justified, even if a normal BMD is found in early adulthood [29].

\section{Acknowledgement}

The authors greatly appreciate the expert help of Amalie Busch and Gisela Hendler for laboratory analyses. S.B. received a grant from Ludwig Maximilians University, Munich (BGF 2011).

\section{Disclosure Statement}

There is no conflict of interest that could be perceived as influencing the impartiality of the research results reported from all authors.

\section{References}

1 Speiser PW, White PC: Congenital adrenal hyperplasia. N Engl J Med 2003;349:776-788.

$\checkmark 2$ Clayton PE, Miller WL, Oberfield SE, Ritzen EM, Sippell WG, Speiser PW: Consensus statement on 21-hydroxylase deficiency from the European Society for Paediatric Endocrinology and the Lawson Wilkins Pediatric Endocrine Society. Horm Res 2002;58:188-195.

3 Debono M, Ross RJ, Newell-Price J: Inadequacies of glucocorticoid replacement and improvements by physiological circadian therapy. Eur J Endocrinol 2009;160:719729.

4 Bachelot A, Chakhtoura Z, Samara-Boustani D, Dulon J, Touraine P, Polak M: Bone health should be an important concern in the care of patients affected by 21-hydroxylase deficiency. Int J Pediatr Endocrinol 2010;2010:326275.
5 Canalis E, Bilezikian JP, Angeli A, Giustina A: Perspectives on glucocorticoid-induced osteoporosis. Bone 2004;34:593-598.

-6 Kasperk CH, Wergedal JE, Farley JR, Linkhart TA, Turner RT, Baylink DJ: Androgens directly stimulate proliferation of bone cells in vitro. Endocrinology 1989;124:1576-1578.

7 Notelovitz M: Androgen effects on bone and muscle. Fertil Steril 2002;77(suppl 4):S34S41.

8 Falhammar H, Filipsson H, Holmdahl G, Janson PO, Nordenskjold A, Hagenfeldt K, Thoren M: Fractures and bone mineral density in adult women with 21-hydroxylase deficiency. J Clin Endocrinol Metab 2007;92: 4643-4649.
9 Gussinye M, Carrascosa A, Potau N, Enrubia M, Vicens-Calvet E, Ibanez L, Yeste D: Bone mineral density in prepubertal and in adolescent and young adult patients with the saltwasting form of congenital adrenal hyperplasia. Pediatrics 1997;100:671-674.

-10 Zimmermann A, Sido PG, Schulze E, Al Khzouz C, Lazea C, Coldea C, Weber MM: Bone mineral density and bone turnover in Romanian children and young adults with classical 21-hydroxylase deficiency are influenced by glucocorticoid replacement therapy. Clin Endocrinol (Oxf) 2009;71:477-484.

-11 Cameron FJ, Kaymakci B, Byrt EA, Ebeling PR, Warne GL, Wark JD: Bone mineral density and body composition in congenital adrenal hyperplasia. J Clin Endocrinol Metab 1995;80:2238-2243. 


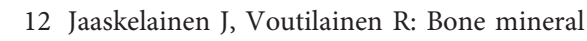
density in relation to glucocorticoid substitution therapy in adult patients with 21-hydroxylase deficiency. Clin Endocrinol (Oxf) 1996; 45:707-713.

13 Bonfig W, Bechtold S, Schmidt H, Knorr D, Schwarz HP: Reduced final height outcome in congenital adrenal hyperplasia under prednisone treatment: deceleration of growth velocity during puberty. J Clin Endocrinol Metab 2007;92:1635-1639.

- 14 Krone N, Braun A, Roscher AA, Knorr D, Schwarz HP: Predicting phenotype in steroid 21-hydroxylase deficiency? Comprehensive genotyping in 155 unrelated, well-defined patients from southern Germany. J Clin Endocrinol Metab 2000;85:1059-1065.

15 Miller W: The adrenal cortex; in Rudolph A, Hoffman J (eds): Pediatrics. Norwalk, Appleton \& Lange, 1991, pp 1584-1613.

16 Brandt I, Reinken L: The growth rate of healthy children in the first 16 years: BonnDortmund Longitudinal Developmental Study (in German). Klin Padiatr 1988;200: 451-456.

17 Neu CM, Manz F, Rauch F, Merkel A, Schoenau E: Bone densities and bone size at the distal radius in healthy children and adolescents: a study using peripheral quantitative computed tomography. Bone 2001;28:227-232.

- 18 Schoenau E, Neu CM, Beck B, Manz F, Rauch $\mathrm{F}$ : Bone mineral content per muscle cross-sectional area as an index of the functional muscle-bone unit. J Bone Miner Res 2002;17: 1095-1101.

19 Tanner JM, Whitehouse RH: Clinical longitudinal standards for height, weight, height velocity, weight velocity, and stages of puberty. Arch Dis Child 1976;51:170-179.

20 Greulich WW, Pyle SI: Radiographic Atlas of Skeletal Development of the Hand and Wrist, ed 2. Palo Alto, Stanford University Press, 1958.
21 Neu CM, Rauch F, Manz F, Schoenau E: Modeling of cross-sectional bone size, mass and geometry at the proximal radius: a study of normal bone development using peripheral quantitative computed tomography. Osteoporos Int 2001;12:538-547.

22 Akaike H: Information measures and model selection. Bull Int Stat Inform 1983;70:14

23 Chakhtoura Z, Bachelot A, Samara-Boustani D, Ruiz JC, Donadille B, Dulon J, ChristinMaitre S, Bouvattier C, Raux-Demay MC, Bouchard P, Carel JC, Leger J, Kuttenn F, Polak M, Touraine P: Impact of total cumulative glucocorticoid dose on bone mineral density in patients with 21-hydroxylase deficiency. Eur J Endocrinol 2008;158:879-887.

24 Mazziotti G, Canalis E, Giustina A: Drug-induced osteoporosis: mechanisms and clinical implications. Am J Med 2010;123:877-884.

25 Buchanan JR, Myers C, Lloyd T, Leuenberger P, Demers LM: Determinants of peak trabecular bone density in women: the role of androgens, estrogen, and exercise. J Bone Miner Res 1988;3:673-680.

26 Cabrera MS, Vogiatzi MG, New MI: Longterm outcome in adult males with classic congenital adrenal hyperplasia. J Clin Endocrinol Metab 2001;86:3070-3078.

27 Cornean RE, Hindmarsh PC, Brook CG: Obesity in 21-hydroxylase-deficient patients. Arch Dis Child 1998;78:261-263.

28 Mora S, Saggion F, Russo G, Weber G, Bellini A, Prinster C, Chiumello G: Bone density in young patients with congenital adrenal hyperplasia. Bone 1996;18:337-340.

29 Stikkelbroeck NM, Oyen WJ, van der Wilt GJ, Hermus AR, Otten BJ: Normal bone mineral density and lean body mass, but increased fat mass, in young adult patients with congenital adrenal hyperplasia. J Clin Endocrinol Metab 2003;88:1036-1042.

30 Paganini C, Radetti G, Livieri C, Braga V, Migliavacca D, Adami S: Height, bone mineral density and bone markers in congenital adrenal hyperplasia. Horm Res 2000;54:164-168.
31 Girgis R, Winter JS: The effects of glucocorticoid replacement therapy on growth, bone mineral density, and bone turnover markers in children with congenital adrenal hyperplasia. J Clin Endocrinol Metab 1997;82:39263929.

32 De Almeida Freire PO, de Lemos-Marini SH, Maciel-Guerra AT, Morcillo AM, Matias Baptista MT, de Mello MP, Guerra G Jr: Classical congenital adrenal hyperplasia due to 21-hydroxylase deficiency: a cross-sectional study of factors involved in bone mineral density. J Bone Miner Metab 2003;21:396-401.

33 Falhammar H, Filipsson Nystrom H, Wedell A, Brismar K, Thoren M: Bone mineral density, bone markers, and fractures in adult males with congenital adrenal hyperplasia. Eur J Endocrinol 2013;168:331-341.

-34 Braatvedt GD, Joyce M, Evans M, Clearwater J, Reid IR: Bone mineral density in patients with treated Addison's disease. Osteoporos Int 1999;10:435-440.

35 Callewaert F, Venken K, Kopchick JJ, Torcasio A, van Lenthe GH, Boonen S, Vanderschueren D: Sexual dimorphism in cortical bone size and strength but not density is determined by independent and time-specific actions of sex steroids and IGF-1: evidence from pubertal mouse models. J Bone Miner Res 2010;25:617-626.

36 Vanderschueren D, Venken K, Ophoff J, Bouillon R, Boonen S: Clinical review: sex steroids and the periosteum - reconsidering the roles of androgens and estrogens in periosteal expansion. J Clin Endocrinol Metab 2006;91: 378-382.

37 Jansson JO, Eden S, Isaksson O: Sexual dimorphism in the control of growth hormone secretion. Endocr Rev 1985;6:128-150. 